\title{
18 Interfaces with syntax in language acquisition
}

\begin{abstract}
We introduce empirical work on Romance language acquisition with respect to the interfaces of syntax with other modules of grammar (internal interfaces) and other domains of cognition (external interfaces). We do so by choosing specific phenomena within the following interfaces: syntax-morphology, syntax-semantics and syntax-pragmatics. In the domain of syntax-morphology we focus on grammatical gender, with respect to the syntax-semantics interface we focus on adjectival placement (pre- and post-nominal) and with regard to the syntax-discourse/pragmatics interface we review work on the null/overt subject distribution. Finally, we summarize research on articles, suggesting that articles represent a multiple interface. We provide examples from different types of learners and across the four major Romance languages French, Italian, Portuguese and Spanish. While our central goal is to summarize and generalize across major findings, we will also point to potential problems concerning the interface approach, e.g. the association of particular phenomena with a specific interface and the assumption that internal interfaces are less problematic than external ones.
\end{abstract}

Keywords: internal interface, external interface, gender, adjective placement, null subjects, pro-drop parameter, articles, determiners, L1 acquisition, 2L1 acquisition, L2 acquisition, eL2 acquisition, heritage speakers

\section{Introduction}

The goal of this chapter is to introduce the reader to the breadth of empirical work on Romance language acquisition with respect to the interfaces of syntax with other modules of grammar (i.e. internal interfaces) and other domains of cognition (i.e. external interfaces). Given this goal and the reality of space limitations, this chapter cannot be exhaustive. We cover all interfaces across different types of learners and across the four Romance languages French, Italian, Portuguese and Spanish, but we chose specific grammatical properties as examples. The work we will focus on as examples is divided across the following interfaces: syntax-morphology, syntaxsemantics and syntax-pragmatics. In the domain of syntax-morphology we focus on grammatical inflection, and specifically grammatical gender. As for the syntaxsemantics interface, we focus on adjectival position (pre- and post-nominal) and its semantic consequences. With regard to the syntax-discourse/pragmatics interface we will review the work on null/overt subject distribution. Finally, we will present 
studies on articles, suggesting that articles might be seen as representing a multiple interface.

It is fitting to start with working definitions of what we mean by the labels and constructs we use. L1 herein refers to child monolingual acquisition (cf. Guasti 2002; Snyder 2007 for review). 2L1 refers to simultaneous acquisition of two first languages, which means naturalistic exposure to two languages from ages zero until the age of 3 (cf. Serratrice 2013 for review). eL2 refers to child second language acquisition by which we are referring to an age of onset of exposure to the second language after the age of 3-4 when the first language has already developed significantly. The distinction between 2L1 and eL2 is made in light of evidence that the latter, despite their young age at the outset of acquisition, display unique patterns diverging from those of monolingual and 2L1 learners (cf. Haznedar 2013 for review as well as Meisel 2009; 2011). Adult L2 learners (henceforth L2ers) refer to the cases of additive or sequential bilingualism when first significant exposure to the L2 occurs after the age of 12, whether or not such exposure in naturalistic or primarily via classroom instruction (cf. White 2003; Slabakova 2013 for review). Finally, heritage speaker bilinguals are the adult outcomes of eL2 or 2L1 acquisition within a specific environment (Montrul 2008; Rothman 2009a). A heritage language is imparted naturalistically from birth either exclusively (the case of eL2 where the L2 is the majority societal language) or simultaneously (the case of 2L1 acquisition). Yet is not the language of the greater society and often becomes the speaker's weaker language in adulthood. In our survey, we exclude the domain of L3 research.

\subsection{What do we mean by an interface?}

Simply put, an interface is the abstraction of where in the space of linguistic computation two sub-systems integrate information. We understand this in terms of formal linguistic (generative) theory, where interfaces have existed, whether by that label or another, since its earliest inceptions. We assume, following a modular view of the mind, that language comprises one domain-specific module, i.e. a grammar (e.g. Chomsky 1957; Fodor 1983; Pinker 1994). Grammar consists of a lexicon and a computational system, connected to each other by means of several internal systems. These internal systems represent the primitive functions of language: lexical inventories (the lexicon and morphology), meaning (semantics), sound (phonology) and the properties that link their correlation (syntax). When different modules of the grammar interface with each other, these are considered "grammar-internal". In addition, the grammar also mediates between sounds and meaning and other not linguistically specific areas of cognition, i.e. "grammar-external” domains, specifically with the articulatory-perceptual system at PF and with the conceptual-intentional system at LF (cf. Figure 1). 


\begin{tabular}{|l|l|l|l|l|}
\hline $\begin{array}{l}\text { Articulatory- } \\
\text { perceptual system }\end{array}$ & PF & $\begin{array}{l}\text { Lexicon and } \\
\text { computational system }\end{array}$ & LF & $\begin{array}{l}\text { Conceptual-intentional } \\
\text { system }\end{array}$ \\
\hline
\end{tabular}

Figure 1: Grammar and interfaces (adapted from White 2009, 51).

The notion of interfaces is completely in line with modularity if one assumes that information is simply shared across domains, while integration of information does not alter the sub-module itself. Furthermore, information structure and conceptual structure may delimit linguistic output and sub-modules interact at various levels to encode and decode language.

\subsection{Why are interfaces relevant for language acquisition?}

In recent years, articulated models schematizing various sub-modules and their interactions have been put forward and applied in language acquisition studies (cf. e.g. Rothman/Slabakova 2011; White 2009; 2011; Rothman/Guijarro-Fuentes 2012 for discussion). One major interest for generative acquisitionists has been to explain why learners have problems even when UG access can be demonstrated. In particular, the question is whether failure to acquire certain structures, prolonged acquisition stages or persistent cross-linguistic influence can be attributed to integrating linguistic information at the interfaces.

The appeal of interfaces applied in language acquisition is not to be understated for several intersecting reasons. As acquisitionists, we are charged with describing and then explaining the initial states, developmental stages and ultimate attainment in all the populations we study. Beyond the classical logical problem of acquisition (e.g. Pinker 1994), there is also the developmental problem (e.g. Hyams 1988), which reminds us to explain why language acquisition unfolds the way it does. The added complexity of information integration, e.g. mapping syntactic function to morphophonological material, integrating contextual cues, mapping prosodic contours to syntactic structure, might prove more or less difficult in the developing grammars of various populations (e.g. child vs. adult; monolingual vs. bilingual) for independent reasons. Such reasons could be that more than one language is present in a single mind or that learners have started to acquire a language at different ages. Indeed, core properties of grammar - the closest things to actual narrow syntactic properties - develop first in all instances of language acquisition (monolingual and bilingual, child and adult alike). Examples include head-directionality and basic word order, which already highlights the special nature of interfaces (cf. Tsimpli 2014 for extensive review).

Our goal herein is not to be evaluative with respect to any specific theory, model or set of hypotheses per se, but rather to contextualize the backdrop for understanding the work we will review below. The important point is that it is easy to understand the appeal of considering interfaces in formal linguistic acquisition studies. 
Considering interfaces in acquisition also creates parsimony between the trends of formal linguistic theory on which we rely and formal approaches to language acquisition. Furthermore, embracing the role that interfaces play in patterns of acquisition embraces the reality of how language actually works within the mind. As stated above, the work on interfaces in language acquisition is now quite considerable and it is no exaggeration to say that studies involving Romance languages have substantially contributed to this general program.

\subsection{The Interface Hypothesis}

A strong proposal in generative acquisition research is that not all interfaces are equal, as highlighted by Sorace's (2011; 2012) Interface Hypothesis. According to the Interface Hypothesis, one effect of bilingualism is an increased processing/resource allocation burden that differentially affects internal and external interfaces. External interfaces are most affected because the relevant integration of information obtains between one (or more) linguistic sub-module(s) and a system that is not domainspecifically linguistic. In other words, phenomena at the external interfaces are particularly vulnerable, i.e. acquired comparatively late, prone to errors, incomplete acquisition and language loss (attrition). Testing the Interface Hypothesis embodies several important empirical questions that have been a focus of the field in recent years. Of course, the idea of syntactic choices being delimited by the discourse context in language acquisition had been around for decades, but it had not necessarily been contextualized in "interface" terms. Since the early 2000s there has been substantial work related to the syntax-discourse interface, specifically on the acquisition of the null subject parameter and related properties in the acquisition of Romance, which eventually gave rise to the Interface Hypothesis (Sorace/Filiaci 2006; Belletti/ Bennati/Sorace 2007). Although there is some disagreement on what exactly an "external interface" is, whether it involves discourse or pragmatics (as well as what these terms mean, cf. Rothman/Slabakova 2011), there is a general agreement of "vulnerability" in this area (cf. Hulk/Müller 2000; Platzack 2001 for ideas predating the Interface Hypothesis; cf. White 2009 for an excellent summary).

In the remainder of this chapter, we review a selection of the literature as detailed above that underscores the importance of the contribution Romance languages have made. We start by summarizing research on grammatical gender in section 2, move on to adjective placement (section 3) and the null subject parameter (section 4) and finally deal with articles in section 5 . In each section we provide a short description of the phenomenon before summarizing relevant work in the acquisition of Romance. We have labelled our phenomena according to the interfaces they are typically attributed to, but we will also allude to cases where these labels are disputable. 


\section{The morphology-syntax interface}

\subsection{Gender}

Gender is a parametrized feature, present in all Romance languages. It is an invariable lexical property of the noun. Other elements, e.g. determiners and adjectives, are gender marked because they are in a syntactic relation with the noun. The attribution of nominal gender is referred to as gender assignment; gender marking of other elements is referred to as gender agreement or concord.

Assignment. Gender assignment in the Romance languages is not random. The four Romance languages discussed here have formal (phonological and morphological) and semantic rules for gender assignment. They vary in the degree to which they employ these rules, but generally formal rules are predominant. For example, in Italian $\sim 70 \%$ of all noun tokens end in $-a$ or in $-o$ in the singular and are feminine or masculine respectively (e.g. mucca $_{\mathrm{F}}$ 'cow', gatto ${ }_{\mathrm{M}}$ 'cat'), thus providing unambiguous formal assignment cues. Portuguese and Spanish are similar to Italian, but French is comparably less transparent. In French, associations of noun endings with particular genders represent probabilistic tendencies with various degrees of reliability. For example, nasal endings are typically associated with masculine gender (e.g. pain $_{\mathrm{M}}$ 'bread', vin $_{\mathrm{M}}$ 'wine', chemin $_{\mathrm{M}}$ 'path' etc.), the suffixes -elle, -ette are typically associated with feminine gender (vaiselle F $_{\mathrm{F}}$ 'dishes', fourchette F $_{\mathrm{F}}$ 'fork'). Languages are masculine ( français $_{\mathrm{M}}$ 'French', espagnol $_{\mathrm{M}}$ 'Spanish'), while sciences tend to be feminine (chimie F 'chemistry', linguistique F 'linguistics'). The described tendencies have psycholinguistic validity because experiments with nonce words have shown that monolingual children and adults assign gender accordingly (Tucker/Lambert/Rigault 1977; Karmiloff-Smith 1979). In all languages, some nouns constitute exceptions to assignment patterns (e.g. Fr. main $_{\mathrm{F}}$ 'hand', It. radio 'radio'), and the number of such exceptions is higher in French than in the other three Romance languages.

Agreement. While nouns have inherent gender, other elements receive gender through agreement with the head noun. Depending on the language, this may include determiners (e.g. articles, demonstratives, interrogative pronouns), adjectives and past participles, e.g. It. le $e_{\mathrm{F}}$ mucche $_{\mathrm{F}}$ nere $_{\mathrm{F}}$, le $_{\mathrm{F}}$ ho viste $_{\mathrm{F}}$ ('the cows black them have-I seen'). Compared to the other Romance languages, gender agreement in less often realized in French, and especially in spoken French. For instance, plural DPs are not gender marked (les chats $_{\mathrm{M}}$ 'the cats' vs. les vaches $_{\mathrm{F}}$ 'the cows') and 2/3 of all adjectives have no audible gender agreement (e.g. $l_{\mathrm{M}}$ chat $_{\mathrm{M}}$ noire vs. la $_{\mathrm{F}}$ vache $_{\mathrm{F}}$ noire 'the black cat vs. the black cow'). Beyond concord, gender marking also involves knowing which morphological forms are associated with each gender, e.g. It. gatto nero $_{\mathrm{M}}$ vs. mucca $_{\mathrm{F}} n e r \underline{\mathrm{F}}_{\mathrm{F}}$. The two processes of (i) concord and (ii) choosing the correct morphological form are related to two different levels, syntax on the one 
hand and phonological form (PF) on the other. Learners vary in how well they acquire the PF-related mechanisms, e.g. the mappings between syntax-semanticsphonology.

The learning task. At first sight, gender acquisition may appear to be a matter of learning lexical and syntactic properties that are reflected in morphology. At a closer look, more is involved. The acquisition of gender involves (i) understanding that gender is an inherent property of the noun; (ii) learning which gender is associated with each individual noun; (iii) discovering that some elements are in a syntactic agreement relation with the noun (and which ones); (iv) learning what morphological forms must be used. To complicate issues even further, in French there is no one to one-correspondence between graphemes and phonemes. For instance, the French word for 'pretty' is spelled differently depending on whether it agrees with a masculine or with a feminine noun ( joli $_{\mathrm{M}}$ garçon $_{\mathrm{M}}$ 'pretty boy' vs. jolie fille $_{\mathrm{F}}$ 'pretty girl'), but the difference is not audible. Such mismatches may have consequences for L2 learners with formal instruction.

\subsection{Gender in L1 and 2L1 learners}

Studies with monolingual children indicate that the acquisition of gender in the Romance languages is relatively problem-free and that children rely on morphophonological cues from a very early age (e.g. Tucker/Lambert/Rigault 1977; KarmiloffSmith 1979; Clark 1985; Pérez Pereira 1991; Kupisch/Müller/Cantone 2002; Corrêa/ Name 2003). Longitudinal studies show error rates below 5\% for monolinguals aged 2-3 years; cf. Pizzuto/Caselli (1992), Chini (1995) for Italian and Kupisch/ Müller/Cantone (2002) for a comparison of Italian and French. The production of "proto-morphemic devices" provides evidence that children start acquiring gender even before age 2 (Bottari/Cipriani/Chilosi 1993/1994). Proto-morphemic devices are placeholders for target morphemes which tend to represent the target-vowel, e.g. [a] (=la) mela 'the apple' vs. [i] (=il) pane 'the bread'. Children's use of such forms suggests that they pay attention to the phonological properties relevant for gender marking from very early on.

Studies with children under the age of 3 are often based on naturalistic data, where the most frequent gender marked element is the article. This explains why the article is often chosen as a diagnostics of (in)correct gender marking, but it comes with the problem that we do not know whether the article form reflects gender assignment or concord (we therefore chose to use the neutral term gender marking here). Another problem is that child data are often not directly comparable to adult data, because the latter tend to be collected in experimental settings in which learners are faced with less frequent nouns, long distance agreement and the arguably more challenging experimental situation. 
2L1 children too show correct gender marking and sensitivity to gender cues from a very early age, but sometimes with slightly more errors than age-matched monolinguals. Kuchenbrandt $(2005,1260)$ reports $~ 90 \%$ accuracy in the Spanish of German-Spanish children aged 2;1-2;3, similar to monolingual Spanish children. For two German-Italian children below age 3, Kupisch/Müller/Cantone (2002) show accuracy above 95\% during the period of inconsistent article use, and 98\% during the period of consistent article use, only minimally higher than monolinguals. Similar results were reported for German-French bilingual children (Müller 1990; 1999). For Swedish-French bilinguals, error rates in French range around 6-8\% at ages 3-4 (Granfeldt 2005). Interestingly, children often have problems with nouns that do not follow general assignment patterns, producing e.g. ${ }^{\star} l e_{\mathrm{M}} \operatorname{maman}_{\mathrm{F}}$ 'the mother', ${ }^{\star} l e_{\mathrm{M}}$ main $_{\mathrm{F}}$ 'the hand' (Müller 1999, 378-379; Kupisch/Müller/Cantone 2002, 138), “ $u n_{\mathrm{M}}$ radio $_{\mathrm{F}}$ 'a radio' (Granfeldt 2003, 217-220). Such errors suggest that they have acquired formal assignment patterns and overuse them, even with nouns that are frequent and semantically transparent, such as maman. Article-noun mismatches are relatively more frequent in cases of strongly unbalanced bilinguals (Granfeldt/Schlyter/Kihlstedt 2007), although they need not result in qualitative differences between L1 and 2L1 development (Kupisch/Müller/Cantone 2002). There are minor differences between L1 and 2L1 children, perhaps unrelated to grammatical gender per se. Since children rely on phonological properties for gender assignment (and article use more generally, cf. section 5), a delayed phonological development due to influence of a simultaneously acquired language - might have implications for gender marking (Kuchenbrandt 2005; 2008; $\lambda 17$ Acquiring multilingual phonologies (2L1, L2 and L3): Are the difficulties in the interfaces?).

\subsection{Gender in adult early bilinguals}

In contrast to early 2L1 acquisition, studies with adult 2L1ers claimed that gender marking can be subject to incomplete acquisition, i.e. deviance from monolinguallike end state grammars. Montrul/Foote/Perpiñán (2008) compared gender agreement in HSs of Spanish in grammaticality judgment and elicitation tasks, showing that they had more problems than monolingual controls.

By contrast, subsequent studies on gender with adult HSs showed that accuracy depends on what exactly is measured. Kupisch/Akpinar/Stöhr (2013) investigated gender marking in 2L1 minority speakers of French and 2L1 majority speakers of French, using an oral acceptability judgment task (henceforth AJT) and picturebased elicitation. In both tasks, the target structures involved article-noun sequences in combination with adjectives (e.g. la fille triste 'the sad girl'). In the analysis, the authors distinguished gender assignment from gender agreement. Articles were taken to be indicators of gender assignment and adjectives indicators of gender agreement. This way, it was possible to determine whether learners were successful 
in marking correct agreement between article and adjective even when choosing an article that did not match the gender of the noun. For instance, la $_{\mathrm{F}}$ chat $_{\mathrm{M}}$ grise $_{\mathrm{F}}$ would count as wrong assignment but correct concord. In the task, learners were purposely confronted with conflicting gender cues. For example, one noun item in the task was sentinelle 'nightguard', which is grammatically feminine (in line with the morphological rule that nouns in -elle are feminine), but the nightguard was contextualized as a male person. The results of this study showed that all bilinguals scored above 95\% in agreement, while having more problems in assignment, especially when nouns involved conflicting gender cues. Hence, gender may appear to be a vulnerable category if one considers gender marking 'as a whole', but, zooming closer, it becomes clear that it is lexical proficiency that creates problems rather than the syntactic mechanism of agreement.

Bianchi (2013) reports similar results for Italian, comparing gender marking on articles and past participles in a study of adult German-Italian 2L1ers from Italy and 2L1ers from Germany. The 2L1ers in Italy performed monolingual-like across the board. By contrast, the 2L1ers in Germany were relatively more accurate when realizing concord between the past participle and the article, while having problems choosing the appropriate article. This was especially true for nouns ending in $-e$, which provide no gender cue (e.g. il dente ${ }_{\mathrm{M}}$ 'the tooth'), and nouns which contradict assignment rules (e.g. masculine nouns ending in - $a$ like il cobra ${ }_{\mathrm{M}}$ 'the cobra'). Thus, the results from adult 2L1s are generally consistent with data from developing bilinguals, revealing that gender agreement is unproblematic in 2L1 acquisition. Furthermore, target-deviant gender marking may be due to the fact that certain, perhaps less familiar nouns provide no gender cues or conflicting ones.

\subsection{Gender in adult L2ers}

In the literature on French it has been widely argued that gender marking causes persistent problems for adult L2ers, especially when the learners' L1(s) do not mark gender; for L2 French cf. Carroll (1989) and Hawkins/Franceschina (2004) (both L1 English), Bartning (2000) and Granfeldt (2005) (both L1 Swedish), Dewaele/Véronique (2001) (L1 Dutch), and Meisel (2009) (child L2ers, L1 German). Based on a review of relevant data on French, Carroll (1989) argued that Anglophone L2ers of French (adults and late immersion students) have great difficulty learning to properly produce French gender marking. She assumes that the absence of gender marking in their L1 determines the (im)possibility of representing the gender feature of nouns in the L2, and if the inherent gender feature of the noun cannot be acquired, this

has implications for gender agreement as well. Similarly, Hawkins/Franceschina (2004) argue that L2ers cannot acquire gender in the L2 if their L1 does not have it, but in their view it is a matter of representing the features relevant for syntactic 
agreement. Both Carroll (1989) and Hawkins/Franceschina (2004) assume fundamental differences between L1 and L2 acquisition. Acquiring gender seems comparatively less problematic for L2 Spanish and L2 Italian learners, but even here researchers differ in the interpretation of their data: Montrul/Foote/Perpiñán (2008) speak of incomplete acquisition, while White et al. (2004) maintain that gender is fully represented in the L2 grammar but for specific reasons it cannot be spelled out correctly. Data from Bianchi (2013) and Kupisch/Akpinar/Stöhr (2013) show that L2ers of French and Italian at an advanced level perform monolingual-like with gender agreement, while assignment may create problems, which parallels the case of 2L1ers, as reported above.

A series of recent neurolinguistic studies have shown that adult L2 learners at high levels of proficiency process gender agreement just like monolinguals. These studies are especially interesting in light of the issues raised by Kupisch and colleagues separating gender "assignment" from "agreement" and with respect to various L2 theories. Full accessibility to UG accounts (e.g. Schwartz/Sprouse 1996; White 2003) predict that the lexical (interpretable) gender features associated with the head noun and the formal (interpretable) features related to agreement across the DP are acquirable for adults, whereas others claim that the latter are unacquirable (Tsimpli/ Dimitrakopoulou's 2007 “Interpretability Hypothesis”). The Interpretability Hypothesis claims that L2 learners use compensatory strategies, predicting better performance in gender assignment due to lexically based strategies. That is, one could interpret the imbalance in agreement and assignment as an inability to acquire the uninterpretable gender features in adulthood (favoring the Interpretability Hypothesis) or simply understand it as a dearth in lexical proficiency at any given time in L2 development continuum. The question of whether the problem with lexically assigned gender is related to lexical proficiency at any given stage of acquisition or an inability to acquire the gender feature is still unresolved. Fortunately, Event Related Potential (ERP) studies can adjudicate between these L2 theories since syntactic violations and phonological rhyme matching elicit distinct ERP signatures, the former eliciting a P600 effect and the latter an N400 effect. Gabriele/Fiorentino/ Alemán Bañón (2013) and Alemán Bañón/Fiorentino (2014) provide evidence from a cross-sectional study on gender assignment/agreement in adult L2 Spanish, strongly suggesting that advanced English-native advanced L2 learners of Spanish can acquire both gender assignment and agreement. Comparing groups of beginning and advanced proficiency levels they showed that the advanced learners elicited a P600 for gender violations. Given that a N400 was not elicited, they concluded that compensatory strategies could not explain the results, that ERP evidence speaks in favor of full UG accessibility and that native-like processing in this domain is attainable through time and exposure to the L2. Most recently, Alemán Bañón/Miller/Rothman (2015) show very similar results to the above studies, this time using morphologically opaque nouns and modulating markedness, whereby advanced L2ers reliably show a P600 like native speakers. 


\subsection{Summary}

Many studies on different learner populations indicate that gender is unproblematic in the acquisition of Romance. Children, both L1 and 2L1, acquire formal assignment rules prior to the age of 3, and the two populations commit the same types of developmental errors, suggesting that in spite of delays they undergo a qualitatively similar process. On the other hand, there are also studies pointing to problems with gender marking, e.g., when compared to other aspects of morphology in French, such as person and tense marking (Thordardóttir, to appear). Disagreement on whether gender is problematic or not is best reflected in research on adult L2ers and the long-lasting debate on whether or not L2ers can ever master gender in a fully native-like fashion. The different views - even among researchers working on the same language (e.g. French) - may hinge on various factors. (i) Gender systems are not equally transparent across languages and not everyone tested the same language; (ii) Experimental and naturalistic are likely to produce different results; (iii) Comparing across studies implies comparing learners with different linguistic backgrounds; (iv) Studies differ in whether they analyzed gender marking on the article, the adjective or both. So, first, when comparing across Romance languages, which individual gender markings appear to be acquired (early, late, never) may be a matter of their frequency, transparency and salience, independently from the syntactic mechanism of agreement. Second, how monolingual-like learners appear to be is a matter of their linguistic background and the method by which they were tested. What does this mean with regard to interfaces? As pointed out by Gaglia/ Hinzelin ( $\lambda 5$ Inflectional verb morphology), scholars do not even agree that there is an independent morphology module, which makes the assumed existence of a syntax-morphology interface framework-dependent. Therefore, even if results from gender appear to substantiate that internal interfaces are comparatively unproblematic in acquisition, this has to be taken with a grain of salt.

\section{The syntax-semantics interface}

\subsection{Adjective placement}

In cases where adjective placement in the Romance languages has been described in interface terms, it has been associated with the syntax-semantics interface (e.g. White 2011; Rothman et al. 2010), since some adjectives in the Romance languages have variable order and differ in meaning depending on whether they precede or follow the noun. In all Romance languages the canonical position for adjectives is after the noun, but some adjectives can appear before the noun as well. It is often said that the adjective in the postnominal position keeps its literal meaning. For instance, grand refers to size in (1a), while expressing a value in (1b). 
(1) Fr. a. Napoléon n' était pas un homme grand. Napoleon NEG was not a man big 'Napoleon was not a tall man.'

b. Van Gogh était un grand artiste. Van Gogh was a big artist 'Van Gogh was a great artist.'

While adjectives denoting size are typical in having variable positions and allowing for value-interpretations, adjectives referring to colors and nationalities appear after the noun with hardly any exception (e.g. Fr. maison rouge vs. ${ }^{*}$ rouge maison 'red house'). Thus, membership in particular semantic classes is relevant for placement options. If adjectives are part of fixed expressions, their position may or may not comply with general rules of adjective placement. For example, alto in the Italian expression in alta montagna 'in the high mountains' refers height (as compared to It. alto ufficiale 'high officer' where it refers to rank), but it nevertheless appears prenominally.

Although adjective placement tends to be seen as a phenomenon at the syntaxsemantics interface, discourse context can be relevant too. For example, Italian povero 'poor' can be used to express pity for someone or that someone has few belongings (cf. 2a vs. 2b).

(2) It. a. Ha ereditato ma è rimasto orfano. Questo

has.he inherited but is remained orphan this

povero ragazzo mi fa pena.

poor boy me makes pain

'He has inherited but he remained an orphan. I'm sorry for this poor boy.'

b. Non può comprare nemmeno una pizza. Ł̀ un ragazzo povero. not can buy not even a pizza is.he a boy poor

'He cannot even buy a pizza. He’s a poor boy.'

In syntactic accounts, it is commonly assumed that adjectives are base generated between the determiner and the noun, and that the postnominal order is derived by noun-movement across the adjective (Cinque 2010). However, some adjectives can be dislocated for stylistic reasons. In these cases, the syntactic derivation might involve the left periphery of the DP, where the DP is linked to discourse (Giusti 2006).

The learning task. Although adjective placement is typically associated with the syntax-semantics interface, it must be acknowledged that using adjectives in the right position involves more, namely (i) determining the semantics classes adjectives and the positioning options for these classes; (ii) determining the meaning associated with each position, (iii) becoming aware that the meanings depend on 
discourse; (iv) learning exceptions, as in fixed expressions and stylistic options. Multilingual learners may have to learn in addition that their target languages have different rules for adjective placement.

\subsection{Adjective placement in L1 and 2L1 learners}

Research on the acquisition of adjective placement in L1 children is comparatively scarce. Cardinaletti/Giusti (2010) reported that L1 Italian children start using a variety of different adjective types before age 3;0 placing them appropriately before or after the noun. Developmental studies on 2L1 children acquiring a Germanic and a Romance language simultaneously show they tend to use adjectives prenominally in the Germanic language and pre- or postnominally in the Romance language, just like monolinguals. However, compared to monolinguals, placement errors occur more often and for a longer period of time. Volterra/Taeschner (1978) were the first to report cross-linguistic influence in the use of adjectives in bilingual children. In fact, drawing on data from two German-Italian 2L1 children (age 2-3 years), they interpreted the occurrence of Adj+N structures in Italian and N+Adj structures in German as evidence in favor of a fused grammar. For a variety of good reasons, their conclusion was later deemed problematic. For example, mixed and monolingual utterances were not considered separately, it was unclear who spoke to the child and whether the adjectives were used as in the predicative or attributive function. Nonetheless, Volterra/Taeschner (1978) were probably right in pointing out that adjective placement is a potentially problematic domain in the $2 \mathrm{~L} 1$ acquisition of a Romance and a Germanic language.

For the past 15 years, research on 2L1 acquisition has tried to systematically predict under which linguistic and extralinguistic conditions cross-linguistic influence occurs. One of the linguistic prerequisites is that one language has two syntactic options (e.g. X and Y), of which only one (e.g. X) is shared by the other. The option that is shared will be overused at the expense of the one existing in only one language (Döpke 1998; Hulk/Müller 2000). The account makes straightforward predictions for adjective placement in a Romance-Germanic context, as discussed by Nicoladis (2006). Nicoladis studied elicited production data in the two languages of EnglishFrench bilinguals (ages 3;3-5;1) and monolinguals in Canada. As expected, the 2L1s produced more reversals of post-nominal adjectives than the L1 children, e.g. *un rayé éléphant 'a striped elephant', and reversals were more frequent in French than in English. Interestingly, however, the 2L1 children overused the postnominal position more frequently than the prenominal position, producing strings like une personne grande 'a big person', contrary to the assumption that bilingual children overuse the structure existing in both languages. By contrast, Rizzi et al. (2013) showed for German-French bilingual children (aged 1;6 to 5;4) that placement errors were equally frequent in prenominal $(60 / 922=6.5 \%)$ and postnominal positions 
$(8 / 135=5.9 \%)$. Similarly, Bernardini (2003) found overuse of prenominal adjectives in a child who acquired Italian as the weaker language and Swedish - language with prenominal adjectives - as his stronger language. Note that children in the latter two studies grew up in a national environment where only the Germanic language was spoken, which may explain their stronger inclination to overuse prenominal adjectives.

\subsection{Adjective placement in adult early bilinguals}

Similar to 2L1 children, adult 2L1s may use adjectives differently from monolinguals, especially in their minority language. Kupisch (2014) employed an oral AJT with German-Italian 2L1s, comparing speakers in Italy with speakers in Germany. The experiment included 42 sentences testing adjective placement, including adjectives which never occur prenominally (e.g. verde 'green', inglese 'English') and adjectives with variable positions (e.g. grande 'big/great'). The speakers' task, under limited response time, was to read and listen to the sentences, judge them, and repeat or correct them depending on their judgment. Some sentences were contextualized and the position of the adjective hinged on the correct interpretation of that context. Results indicated that learners had more problems using adjectives with variable positions correctly (e.g. grande) than adjectives that are consistently postnominal (e.g. verde). The percentage of correct responses was $97.4 \%$ for the $2 \mathrm{~L} 1 \mathrm{~s}$ from Italy and $82.6 \%$ for the $2 \mathrm{~L} 1 \mathrm{~s}$ from Germany. Since the speakers from Italy had more exposure to Italian and used the language more often, the results suggest that input quantity and quality determine acquisition outcomes. Interestingly, when producing adjective-noun strings in the wrong order, the learners were more likely to overuse postnominal adjectives. This result is consistent with Nicoladis' (2006) findings, while contradicting the idea that what is present in both languages will be overused. Kupisch (2014) further studied adjective placement in the spontaneous speech of the same speakers, finding that placement errors were close to absent (less than 1.5\% in more than 1200 adjectives). In a similar study on French with German-French 2L1s (Kupisch et al. 2014), speakers from Germany performed with a mean of $90 \%$ accuracy and speakers from France with 98\% accuracy. The few cases where the bilinguals did not perform monolingual-like mostly involved fixed expressions. Unlike in previous studies, the minority speakers had attended schools in the minority language, which might explain their comparatively high accuracy.

\subsection{Adjective placement in L2 acquisition}

Coppieters (1987) tested near-native L2ers of French, using a metalinguistic task in which L2ers were asked to articulate the meanings of sentences with pre- or postnominal adjectives. The L2ers often failed to articulate the subtle differences in 
meaning between prenominal and postnominal adjectives. These results could be taken to suggest they had a problem with the interface between word order (a syntactic property) and interpretation (a semantic property). However, Coppieters did not contextualize the sentences, although, as we illustrated in (2) above, context can be essential for adjective meaning. Indeed, Anderson (2008) and Rothman et al. (2010) came to different results using different tasks when testing L2 French and Spanish speakers. Anderson employed a grammaticality judgment task with contextualized utterances, and Rothman et al. (2010) used a semantic interpretation tasks in which the L2ers had to select one of two possible interpretations. In both studies, the L2ers were comparatively more successful in using and interpreting adjectives.

\subsection{Summary}

Adjective placement appears to be more vulnerable in bilingual leaners than in monolinguals. However, the observed error patterns do not provide a uniform picture. Some studies report overuse of the prenominal position, others of the postnominal position, and deviance from monolinguals varies with learner types and methods. As with grammatical gender, there is an open debate on whether L2ers can acquire monolingual-like proficiency. So what does the empirical evidence tell us about interface issues? The question is hard to answer. (i) Adjective placement is primarily a matter of the syntax-semantics interface, but not exclusively. Variability, lexical knowledge and discourse factors play an additional role. So attributing the phenomenon to an internal interface (exclusively) is not without problems. (ii) Existing studies vary in the type of data collection (e.g. isolated vs. contextualized test sentences, naturalistic vs. experimental data). (iii) There are barely any direct comparisons of adjective placement with other phenomena based on the same learners and methods. Thus, for this phenomenon comparatively vulnerability and the associated interface need to be investigated further.

\section{The syntax-pragmatics interface}

\subsection{Pronominal subjects in Romance languages}

The minimal universal structure of a sentence requires two elements: subject and predicate. We assume that the obligatory nature of subjects is a principle of grammar. However, whether or not subjects have to be morphophonologically expressed is a parameterized property, covered under the Null Subject Parameter (NSP), also known as pro-Drop Parameter (e.g. Rizzi 1982; Jaeggli/Safir 1989; Alexiadou/ Anagnostopoulou 1998; Camacho 2013). Since all human languages have overt pronominal subjects, the setting of this parameter regards whether or not a language 
can also license null pronominal subjects and, in case it does, what the linguistic representational properties are that result in such licensing. Not all null subject languages have the same underlying representation. For example, the licensing of null subjects can be a syntactic reflex of rich verbal morphological agreement, as in Romance languages, or they can be licensed pragmatically in languages that have little or no verbal agreement, as in Chinese. The Romance language family is particularly interesting since there is substantial variation, ranging from French not allowing null subjects - to Brazilian Portuguese -undergoing diachronic change towards losing its null subject grammar - to Italian, European Portuguese and Spanish, which are null subject languages in a classic sense. Brazilian Portuguese stands out from the other Romance null subject languages in that its verbal morphology, which is assumed to be linked to the licensing of null subjects of the Romance type, is greatly reduced (Holmberg/Nayudu/Sheehan 2009). It marks only three grammatical persons overtly in the standard, and as little as two in colloquial dialects, and there is a general preference for overt subjects, perhaps as a result of the aforementioned. There are also numerous Northern Italian dialects whose status as null subject languages has been subject to debate and, typically, these dialects display more syncretism in their verb morphology than Standard Italian. For ease of exposition, we will simplify and claim that despite subtle differences Italian, European Portuguese and Spanish are essentially the same whereby the null subject is the default. In these languages, overt subjects arise for specific discourse functions such as [+contrastive focus] and [+topic shift], and they are superfluous and pragmatically infelicitous outside of these specific discourse contexts. For example, in (3) below, given that contrasting between "you" and "Marta" is inherent, only (3a) is felicitous, despite the fact that the second person morphology on the verb hagas already disambiguates between 2nd and 3rd person reference. Contrastive focus requires overt subjects; thus (3b), though grammatical, sounds pragmatically odd. Note that in both (3a) and (3b) the subject of the matrix verb does not overtly appear. It would in fact be equally pragmatically odd for it to overtly appear since the verbal morphology clarifies the reference antecedent and there is no apparent discourse function to warrant its use.

(3) Sp. a. Quiero que lo hagas TÚ y no Marta. want.I that it do you and not Marta.

b. ?Quiero que lo hagas _ y no Marta. want.I that it do _ and not Marta. 'I want you to do it and not Marta.'

The learning task. Complete knowledge of pronominal subjects in null subject languages implies acquiring the syntax of a language that licenses null subjects as well as knowing the distribution of overt and null subjects in this language. In the 
framework we are adopting, other properties which are linked to the NSP as part of the clustering of properties should come 'for free', i.e., with the right setting of the parameter, for example, that expletive subjects are obligatorily null.

\subsection{Pronominal subject distribution in L1 and 2L1}

In first language acquisition, children produce null subjects irrespective of whether or not the target adult grammar is a null-subject grammar. In fact, at very young ages sentence production is minimal and sentences without subjects (e.g. eat apple) are common. That is, even French and English children omit subjects initially and progressively less over time. This same pattern is also true of L1 children of null subject grammars such as Spanish, European Portuguese and Italian, where null subjects are $100 \%$ and decrease to reflect the adult pragmatic distribution over time (e.g. Austin et al. 1997; Grinstead 2004). Hyams (1986) and Hyams/Wexler (1993) explained this by assuming that all children start as a default with the positive setting of the NSP. Valian (1991) and Rizzi (1994; 2002) question this, however, pointing out that children of Romance languages like Spanish, Italian and Portuguese produce much higher rates of null subjects, roughly $70 \%$, as compared to English speaking children at around 30\%. Rizzi further points out that the contexts in which Romance children produce null subjects are different, including subjects of matrix inflected verbs in embedded and interrogative clauses, whereas English and French children largely produce null subjects with root infinitives and very rarely when the verb is inflected.

As mentioned, the first stage of acquisition for Spanish children involves close to $100 \%$ use of null subjects, at least in 3rd person contexts, and decreases over time. According to Grinstead (2004), this change is directly proportional with the availability of the CP field, which according to some theories can be related to the development of pragmatic competence. In his data examining production of Spanish and Catalan, Grinstead shows a correlation with the emergence of overt subjects used pragmatically appropriately with other CP dependent structures. Bel (2001; 2003) also investigated data from child Spanish, showing upwards of 30\% of overt subject use from early on with essentially no increase or decrease over time. Similarly, Guasti (1993/1994) and Valian/Eisenberg (1996) showed for Italian and European Portuguese that null subjects have roughly the same frequency and distribution as in the adult grammars, occurring in both root and subordinate clauses. From the available sources it is clear that L1 children acquire the distribution of pronominal subjects quite early and this seems to be true of all relevant Romance languages.

There is also evidence that dialectal variation is attuned to by the child, as reflected in diverging developmental patterns when the adult baseline grammar is different. Ticio (2002) examined data of a Puerto Rican L1 Spanish child, a dialect 
of Spanish that like Brazilian Portuguese has been undergoing progressive weakening of its morphological agreement paradigms. Unlike the Spanish children studied by Grinstead (2004), this Puerto Rican child never goes through a stage of $100 \%$ null subjects. However, the data also are distinct from Bel's (2001; 2003), who showed a 30\% use of overt subjects in her subject's Spanish. Instead, Ticio reports an 18\% use of overt subjects in the first stage. While we do not know of any comparable L1 Brazilian Portuguese data, we might predict that differences between European and Brazilian Portuguese would also obtain, even more drastically than what Ticio (2002) shows for dialectal variation in Spanish, given the even greater use of overt subjects in Brazilian Portuguese and its more pronounced weakening of verb morphology as compared to Caribbean Spanish.

There is some evidence that 2L1 children have more problems than L1 children in acquiring the properties pertaining to the NSP. Paradis/Navarro (2003) examine the production of Manuela, a 2L1 speaker exposed to Cuban Spanish and English. Compared to L1 Spanish children, Manuela used more overt subjects in Spanish from the earliest stage, and postverbal subjects were absent from her speech. Moreover, 32\% of Manuela's overt subjects were infelicitous in the given discourse context, which contrasts sharply from the under $10 \%$ of pragmatic oddness reported in Grinstead (2004) and Ticio (2002) (the latter for Puerto Rican Spanish). Thus, the fact that Manuela was exposed to Cuban Spanish would not explain everything. Based on these differences, Paradis/Navarro (2003) concluded that the syntax of Manuela was different from that of monolingual L1 children and subject to cross-linguistic influence from English. Work by Serratrice (2007) supports that subject use is affected by cross-linguistic influence. In her study, Italian L1 children were far less likely than 2L1 English-Italian children to accept an overt third person pronoun as co-referential with a subject antecedent.

Sorace's (2011 inter alia) claim that there should be protracted development in 2L1 acquisition at the syntax-pragmatics interface was based in particular on data pertaining to the null subject property. Paradis/Navarro (2003) and Serratrice (2007) had shown evidence for this already, but Sorace's claim is not based on crosslinguistic influence per se, although it does not preclude an effect of language pairing either. Rather, differences between bilinguals and monolinguals are seen as a more general consequence of bilingualism. For processing reasons, more overt subjects in pragmatically odd environments and/or unexpected anaphoric resolution with overt subjects should obtain in all bilinguals even if both languages are null subject grammars (Sorace/Serratrice 2009; Sorace 2011). This claim is, however, not necessarily defensible in light of Basque-Spanish 2L1 data. Ezeizabarrena (2002) shows that Basque-Spanish 2L1 children develop equally to monolinguals with respect to subjects in both their languages, so a delay when both languages are null subject languages does not always obtain. Ezeizabarrena's study shows that protracted development at the syntax-discourse interface is a not a necessary consequence of 2L1 development, which asks us to consider, at least in tandem, other variables that 
conspire to explain the apparent greater vulnerability of this interface with some 2L1 pairings as compared to others.

\subsection{Pronominal subjects in adult early bilinguals}

Montrul (2004) investigated the syntax of pronominal subjects and its discourse integration with Mexican-American heritage speakers of Spanish. Her study shows that heritage speakers have no issues with the syntax of null subjects, omitting subjects in the same contexts as monolinguals. However, their use of subjects was pragmatically marked, as they used them in contexts in which monolinguals would drop the subject. Montrul suggests that the heritage speakers' expanded domain of overt pronoun use might reflect an influence from English. It is an open question as to what the sources are for the noted difference, as it is possible that the patterns shown by heritage speakers are not actually influence from English at all but reflect a different distribution in the input that is provided to them by speakers who are likely undergoing attrition themselves. In other words, their sources of primary linguistic data are immigrants who are themselves increasingly bilingual, as suggested by Sorace (2004) in her reply to Montrul's article (cf. Rothman 2007; Pires/Rothman 2009).

\subsection{Pronominal subjects in L2 acquisition}

The Null Subject Parameter is perhaps the most widely studied domain in adult L2 Romance language acquisition. Seminal studies from the beginning of generative SLA clearly include those examining the (re)-setting of this parameter (e.g. White 1985; 1986; Muñoz Liceras 1989; Hilles 1986; Phinney 1987). Studies looked at adult L2ers of Spanish who were natives of English and French as well as Spanish natives acquiring English. These studies showed consistently that speakers of non pro-drop languages were able to acquire the null subject property relatively easily, whereas speakers starting with a null subject grammar had more difficulties un-learning null subject licensing. Muñoz Liceras (1989) also showed successful acquisition of the null subject property in L2 Spanish, but her learners failed to demonstrate full knowledge of the parameter's claimed cluster of properties (Rizzi 1982), such as the lack of that-trace effects and subject-verb inversion, leading her to claim that the clustering effect of parametric learning did not pertain to adult L2ers (but cf. Rothman/Iverson 2007a; 2007b for an alternative view).

Throughout the 1990s and the 2000s, other domains of grammar relating to the syntax-semantics and the syntax-discourse interfaces and pronominal subjects were tested in L2 Spanish. Pérez-Leroux/Glass (1999) tested learners' knowledge of the Overt Pronoun Constraint (OPC) (Montalbetti 1984), a claimed universal syntaxsemantics restriction that precludes bound variable interpretations in languages that have null-subjects only, which can been seen in (4) and (5). 
(4) a. The girl $\mathrm{i}_{\mathrm{i}}$ thinks that she $_{\mathrm{i} / \mathrm{j}}$ is tall.

b. Each $\operatorname{girl}_{\mathrm{i}}$ thinks she $\mathrm{i}_{\mathrm{i} / \mathrm{j}}$ is tall.

(5)
a. La chica $a_{i}$ cree que ella $a_{i / j}$ es alta. the girl thinks that she is tall
b. La chica ${ }_{\mathrm{i}}$ cree que pro $_{\mathrm{i} / \mathrm{j}}$ es alta. the girl thinks that is tall
c. Cada chica ella $_{\star_{\mathrm{i} / \mathrm{j}}}$ es alta. each girl thinks that she is tall

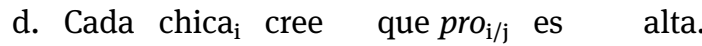 each girl thinks that is tall

In English, the OPC does not apply, and so the embedded pronoun she in (4a) and (4b) can be either co-referential with the matrix subject 'the girl/each girl' or take disjoint reference, referring to some other girl. In the Spanish examples in (5), both interpretations are available for (5a) and (5b) since the matrix subject - the DP - is not a variable expression. In (5c), by contrast, the matrix subject, being a quantified DP, is a variable expression and thus co-reference between the overt embedded subject in (5c) and the matrix variable expression is precluded by the OPC. Only a disjoint reference is possible. However, (5d) is ambiguous to the same extent as (5a) and $(5 \mathrm{~b})$ because the OPC only constrains bound variable interpretations for overt subjects. It is prudent to note that there is nothing pragmatic about the OPC. In other words, its restrictions are not dependent on context per se, but rather the syntactic environment.

In a contextualized translation task, Pérez-Leroux/Glass (1999) showed that even intermediate learners of Spanish avoided supplying overt subjects in bound variable contexts - where the context pushes co-reference and the matrix subject of the embedded pronoun is a variable, quantified DP (as in 5c) or wh-element - and advanced learners performed completely like native speakers. This would mean that in translating sentences like (4b) above, learners rarely used an overt pronoun in the embedded clause and certainly highly significantly less than in their translations of sentences like (4a). Rothman/Iverson (2007a; 2007b), using a different methodology, showed the same results in both naturalistic and classroom L2ers of intermediate and advanced proficiency levels. Lozano (2002) also demonstrated success in OPC restrictions in L2 Spanish, but a lack of similar success levels in the pragmatic distribution of null and overt subjects in the same learners. Lozano's (2002) study is one of the earliest examining directly the L2 acquisition of discourse conditions of the distribution of pronominal subjects in Romance. It revealed that knowing the syntax of subjects (i.e. whether or not the target language is a null subject language) 
and even the syntax-semantic restrictions on their use (e.g. knowledge of the OPC) did not entail full knowledge of the discourse felicity conditions on their distribution. Later work on pronominal subjects in L2 Romance (e.g. Sorace/Filiaci 2006; Belletti/Bennati/Sorace 2007) played a substantial role when Sorace (2011) formulated the Interface Hypothesis. Sorace and colleagues tested near native speakers of L2 Italian, showing that despite sophisticated knowledge of the syntax, L2ers were significantly different from Italian natives, producing more overt subject pronouns in environments of topic-maintenance where they are unexpected.

Challenging the Interface Hypothesis, Rothman (2007; 2009b) showed that although the syntax of the NSP is acquired before related discourse constraints on subject distribution, advanced L2ers of Spanish could perform with no differences to monolinguals. Differently from Sorace and colleagues' work, Rothman focused on null vs. overt subjects in contrastive focus environments as compared to neutral environments (cf. example 3 above, cf. also Madeira/Xavier/Crispim (2012) for similar results in L2 European Portuguese). In sum, it seems that developmentally speaking there is a delay of syntax-discourse interface properties, but such a delay does not result inevitably in residual optionality.

\subsection{Summary}

It is clear from the large body of research across all groups of language acquirers that the syntax-discourse/pragmatics interface, as exemplified by the NSP, conveys difficulties and delays across all learner groups, perhaps more than other interfaces, as argued by the Interface Hypothesis (Serratrice et al. 2009; Sorace 2011). However, indicators of comparative difficulty, e.g. rates of pragmatically inappropriate subject pronouns, very much depend on who is tested and by what methods. Again, without data from one the same population tested in different interfaces and using similar data types (e.g. naturalistic or experimental data), we should be wary of coming to final conclusions.

\section{Multiple interfaces}

\subsection{Articles use}

In the acquisition literature, articles have often been associated with the syntaxsemantics interface (Serratrice et al. 2009; Montrul/Ionin 2010) because their presence vs. absence can be used to encode differences in meaning. For example, I like the cats differs from I like cats in referring to a specific group of cats (specific reference) as opposed to cats in general (generic reference). However, it would be inappropriate to leave it at that. Articles are morphemes which, depending on the language, 
may encode also formal functions such as gender (cf. section 2), number and case. Whether an article is used or omitted may depend on the syntactic function of the DP it is part of (subject vs. object, predicate vs. argument). Furthermore, there has been influential work on how prosodic aspects determine article development in L1 and L2 acquisition (e.g. Lleó/Demuth 1999; Goad/White 2009), as well as work on the discourse functions of articles (e.g. Hickmann/Hendriks 1999; Kupisch 2007; Rozendaal 2008). It is hence fair to say that, more than the other phenomena considered so far, articles represent a multiple interface. This does of course not preclude the possibility that specific aspects of article use can be studied in isolation, as pointed out above for gender marking.

Closely connected to its multiple interface nature is the plurifunctionality of articles, illustrated in (6) for the Italian indefinite singular article. In (6a), the DP refers to a specific cat; nonetheless the DP is 'indefinite' because this cat is deemed to be unknown to the addressee. In (6b), the referent has not even been individuated or 'specified' by the speaker, thus being non-specific. In (6c), again, no specific individual has been singled out, but the referent can be considered definite because it can be presupposed that the generic category, i.e. the abstract category of 'cats', is familiar to the addressee.

(6) It. a. Ho un gatto, che si chiama Carlo.

(specific, indefinite)

'I have a cat, whose name is Carlo.'

b. Un giorno avrò un gatto, ma non so quale. (non-specific, indefinite) 'One day I will have a cat but I don't know which one.'

c. Un gatto è un animale a quattro zampe. (non-specific, definite/generic) 'A cat is an animal with four paws.'

The Romance languages have both definite and indefinite articles, and these are mostly marked for gender and number. The grammaticalization of articles in the Romance languages is comparatively advanced, as witnessed by the fact that articles are obligatory except in a small number of well-defined contexts (Longobardi 1994; Chierchia 1998). Compared to the Germanic family, the Romance languages have indefinite plural articles (e.g. It. Mangio delle patate 'I eat (of the) potatoes'), although they are not obligatory to the same degree across these languages. Another particularity of the Romance languages is the obligatoriness of articles with generic DPs in the plural (e.g. I gatti dormono molto 'Cats sleep a lot'). Portuguese and Italian further require articles before possessive pronouns, e.g. It. il mio gatto and Ptg. o meu gato '(the) my cat' and both languages allow articles before proper names; French and Spanish permit no articles in comparable contexts. When it comes to 'bare nouns', i.e. nouns without articles, French is considered to the most restrictive language (Roodenburg 2005) and Portuguese the least restrictive one, 
allowing bare nouns even with generic plural DPs (Munn/Schmitt 1999). Most Romance languages are subject to dialectal variation, e.g. across the Italian varieties or between European and Brazilian Portuguese.

The learning task. Articles are morphological elements with numerous functions. The learning task in Romance involves at least (i) discovering that the target-language has articles, which may be facilitated or inhibited by the prosodic properties of articles and previously learnt languages; (ii) determine their formal functions (gender and number marking) and use the associated morphological forms; (iii) determine the syntactic dimensions along which article use varies; (iv) understand the semantic and discourse functions of articles; (v) awareness of dialectal variation. Although these different dimensions may be studied in tasks that try to isolate them, cumulative difficulties may nonetheless arise. For example, learners may fail to provide a semantically appropriate article, because they concentrate on other aspects of article use, e.g. correct gender marking.

\subsection{Articles in L1 and 2L1 learners}

Article acquisition is a well-documented phenomenon in the early speech of children acquiring a Romance language. Extant research has been concerned with omissions in obligatory contexts, morphologically, semantically or pragmatically correct article choice, or a combination thereof. Here, we leave the morphological aspect aside (cf. section 2).

L1 acquisition of articles may involve the following stages: (ii) a bare-noun stage when nouns occur without determiners, (ii) a stage with proto-articles, (iii) a variation stage where bare nouns and nouns with determiners co-occur, and (iv) a target stage where nouns are used with determiners whenever required. The proto-article stage is deemed typical of Romance-learning children (e.g. Bottari/Cipriani/Chilosi 1993/1994; Lleó/Demuth 1999; cf. also section 2), though not excluded for Germanic either. Italian- and French-learning children use their first articles around 1;6 and no later than age 2;0 (cf. Pizzuto/Caselli 1992; Antelmi 1997 for Italian; Bassano/ Maillochon/Mottet 2008; Bassano et al. 2013a; van der Velde/Jakubowicz/Rigaut 2002 for French). For Italian, Bottari/Cipriani/Chilosi (1993/1994, 340) observed protoarticles ("fillers", "placeholders" or "proto-morphemic devices") from age 1;8 onwards. As mentioned in section 2, these are phonologically reduced forms, consisting of a single vowel - either a neutral (central) one or the target vowel, e.g. [ə] cane, [e] cane or [i] cane instead of il cane 'the dog'. Given that such fillers mark the syntactic position of articles, their occurrence suggests that the children's morphological development lags behind their syntactic development. As for order of appearance, definite and indefinite articles tend to appear before other determiners like possessives and demonstratives, but there are individual exceptions (e.g. Bassano/Maillochon/ 
Mottet 2008; Bassano et al. 2013b). Based on cross-sectional data from French children in three age groups (1;8, 2;6 and 3;3), Bassano/Maillochon/Mottet (2008) further found that articles appeared earlier with monosyllabic nouns than with multisyllabic ones.

L1 children generally cease to omit articles in obligatory contexts before they turn 3;0 and most work on children acquiring a Romance report that they do so even earlier around 2;6 (cf. Pizzuto/Caselli 1992; Caselli et al. 1993; Kupisch 2007 for Italian; Guasti et al. 2004 for Catalan). A substantial amount of work has tried to show that how fast children converge on their target system depends on the properties of the target language. It was argued that children acquiring a Romance language omit determiners less frequently than children acquiring other languages and cease to omit them with a lower Mean Length of Utterances (MLU) and at earlier ages as compared to children acquiring Germanic languages (Chierchia/Guasti/ Gualmini 1999; Lleó/Demuth 1999; Lleó 2001; Guasti et al. 2004; Kupisch 2007; Rozendaal/Baker 2008; Bassano et al. 2013a; 2013b). There is no consensus what causes these differences. The most influential accounts were based on semantics (Chierchia 1998) and prosody (Lleó/Demuth 1999). However, the semantic account has been subject to criticism, because it treats all Romance and all Germanic languages as if they were alike. In fact, there is substantial variation within these families, concerning both the target systems and their acquisition (cf. Bohnacker 1997; Kupisch et al. 2009).

Studies on 2L1 children have mostly dealt with children acquiring Romance and Germanic languages simultaneously. These children follow the same developmental paths as monolingual children, but there may be delays in the production of Romance articles (e.g. Granfeldt 2000; Hulk 2004) or acceleration in their production of Germanic articles (Kupisch 2007). Given some overlap in the conditions of article use in Germanic and Romance, cross-linguistic influence has been more intensively studied in the contexts where the two language families exhibit contrasts. In the plural, Romance definite DPs are ambiguous between a specific and a generic reading (7b). By contrast, Germanic plural definites tend to have a specific reading (7a), while expressing the generic reading through bare nominals (7c), which, in turn, are ungrammatical in Romance (cf. 7d).

(7) a. Engl. The sunflowers are yellow. [+specific, -generic]

b. It. I girasoli sono gialli. [+specific, +generic]

c. Engl. Sunflowers are yellow. [-specific, + generic]

d. It. ${ }^{\star}$ Girasoli sono gialli.

Since generic DPs are infrequent in spontaneous speech, most relevant data comes from experiments. In contexts like $(7 \mathrm{a}, \mathrm{b})$, L1 children favor a generic interpretation, even in languages like English that do not allow this interpretation (cf. PérezLeroux et al. 2004 for Spanish and English, Kupisch/Pierantozzi 2010 for German 
and Italian). Over time, English children learn that only the specific reading is available for such DPs in their target language. As for 2L1 acquisition, German-Italian children at primary school age were shown to be more inclined to interpret Italian sentences like (7b) as specific compared to monolingual Italian children at comparable ages (Kupisch/Pierantozzi 2010). In an AJT, Italian-English school children were less likely than monolingual Italian children to correct ungrammatical generic sentences lacking the article like in (7d) (Serratrice et al. 2009). In summary, 2L1 studies witness cross-linguistic influence in production, interpretation and acceptability judgments.

A number of studies also looked at the emergence of discourse functions of articles, such as naming/labelling and identifying. The data from children acquiring Romance languages mirrors that of English-learning children. Generally, they use articles in different functions from early on, starting with the labelling and identifying function. One of the more difficult functions is the use of the indefinite article to signal that a referent is unknown to the addressee of the utterance, as in (6a). Here, children often overuse definite articles, committing so-called "egocentric errors", which means that they fail to take their listener's view into account (cf. KarmiloffSmith 1979 for French, Kupisch 2006 for German-French and German-Italian bilinguals, Rozendaal 2008 for a comparison of Dutch, English and French children). There is further evidence that young children's determiner use is related to general discourse factors. For instance, determiner use tends to be more frequent with given (vs. new) referents and with referents present in the nonlinguistic context (vs. absent ones) (cf. Bassano et al. 2013b for a longitudinal study of six French children at 1;8, $2 ; 6$ and $3 ; 3)$.

\subsection{Articles in adult early bilinguals}

Montrul/Ionin (2010) and Kupisch (2012) tested the ability of heritage speakers of Spanish and Italian to use articles with specific and generic plural DPs of the type in (7b), using AJTs and truth value judgments tasks (TVJTs). In the latter, learners were for instance presented with sentences of the type Los elefantes tienen colmillos de marfil '(The) Elephants have ivory tusks'. The relevant question is whether children would judge the sentence as true even when they are faced with elephants without ivory tusks. Under the influence of English, learners might be more inclined to interpret the sentence as having specific reference, thus judging the sentence as "false" in a context where elephants without ivory are presented. The reason is that definite plural subjects in English only allow the specific interpretation, as in (7a). In an AJT, the same learners had to judge the acceptability of generic nouns without a plural article, which are ungrammatical in Spanish but whose literal translations are fine in English (cf. 7c and 7d). They often accepted inappropriate plural subjects lacking the article. In Kupisch's (2012) study, the 
heritage speakers performed more similar to L1 Italian speakers in the TVJT than in the AJT, suggesting advantages in tasks which are more intuition based as compared to tasks which are more similar to an L2 learning context, such as grammaticality judgments. In a study with adult 2L1 speakers of French using the exact same design, Barton (2015) showed ceiling performance. However, her 2L1 learners though growing up in Germany - had attended French schools, which may explain why they looked more similar to monolinguals. Furthermore, 2L1s who speak a Romance language as their majority language, perform just like monolinguals. This indicates that the extra-linguistic environment and the type of schooling play an essential role for how monolingual-like learners will end up being.

\subsection{Articles in L2 acquisition}

Article use is notoriously difficult for L2ers whose L1 does not have articles, such as Korean, Russian or Turkish. We know that L2ers misuse, overuse or omit articles for various reasons, including problems relating to how the [ \pm definiteness] feature is represented in the interlanguage grammar. For example Ionin/Ko/Wexler (2004) proposed that L2ers whose L1s lack articles fluctuate between definiteness and specificity, i.e. the features that govern article choice. Tsimpli/Mastropavlou (2007) suggested that there will be permanent morphosyntactic deficits in cases where the L2 instantiates an uninterpretable definiteness feature that is inexistent in the L1. Trenkic (2007) attributed problems with article use to persistent pragmatic problems. Goad/White (2009) argued that L1 prosodic representations may be transferred to the L2, and these representations may be such that independently of the issue of definiteness L2 cannot be pronounced or is done inconsistently. On the other hand, there is also research showing that even the most subtle semantic contrasts can be acquired at advanced stages of acquisition. In the following, we will once more concentrate on the difference between specific and generic readings, because most studies on L2 Romance have investigated learners whose L1 was either German or English, and for whom this distinction represents a major area of difficulty.

Ionin/Montrul (2009; 2010) investigated L1 transfer in Spanish learners of English in specific and generic plural DPs. The conditions were similar to those outlined above for adult early bilinguals. While Spanish L2ers at intermediate levels showed L1 transfer, more advanced learners recovered from L1 transfer, interpreting definite and bare plurals in a target-like way (cf. Ionin/Ko/Wexler 2014 for a similar study on Brazilian Portuguese highlighting the role register and/or input and Kupisch 2012 for L2 Italian).

In a slightly different type of study, Slabakova (2006) examined the interpretation of bare and definite plurals by L1 English learners of L2 Italian. One semantic contrast between English and Italian is that while English bare NPs can have either a generic (all) or an existential (some) meaning, e.g. for sentences like "White elephants will undergo the final judgment tomorrow at 5". Italian, by contrast, has 
only an existential interpretation, i.e. "Some white elephants will undergo the final judgment tomorrow at 5". Another semantic contrast relates to sentences such as "Large cats think very highly of themselves". In English, the sentence can have a kind reading, meaning that every large cat has a high opinion of all large cats as a species. The English sentence can also have a distributive reading, i.e. that each individual large cat has a high opinion of itself only, but they may not think highly of the species in general. In Italian only the distributive reading is available. A written TVJT revealed that the L2 Italian learners at advanced levels performed like Italian native controls, suggesting that with advanced proficiency, L2ers can acquire extremely subtle meaning differences. Cuza et al. (2013) provided similar results for L1 English learners of L2 Spanish at the advanced levels of proficiency.

\subsection{Summary}

Summarizing, L1 research indicated that articles appear very early in the speech of Romance learning children, i.e. before age 2;0. Although L1 learners use articles from early on, some article functions are acquired comparatively late, e.g. the generic function and the specific indefinite use of the indefinite article. 2L1 learners seem to pattern with L1 learners but they may show delays and increased difficulty or acceleration and facilitation, depending on the language combination and their relative proficiency. L2 learners can acquire even the most subtle aspects of article use if they are advanced enough, and heritage speakers have similar problems as L2ers, but their performance may be task dependent. What does this mean with respect to interfaces? It is first of all remarkable that a phenomenon as complex as articles can be acquired at all and that article have not figured as prominently in the interface literature as the null subject parameter. It has indeed been argued in a comparison of the same groups of Italian-English learners that articles (syntaxsemantics interface) are less vulnerable than subject pronouns (syntax-discourse interface) (Sorace/Serratrice 2009), but there are also studies with adult heritage speakers, showing that they do not use articles akin to monolinguals (Montrul/Ionin 2010; Kupisch 2012). Again, how complex a phenomenon appears to be in an acquisition study depends at least partially on the group of selected learners and the chosen design.

\section{Conclusions}

Research pertaining to interface conditioned properties in language acquisition dates back longer than the term itself, and research on the acquisition of Romance languages has contributed substantially to our understanding of interfaces. Nevertheless, we feel that we are not yet in a position to claim, at last not based on acquisition data, that one or the other interface is more or less vulnerable in acquisition. It 
is even possible that there are types of cross-language interaction that are independent of interfaces, as argued by Lleó ( $\lambda 17$ Acquiring multilingual phonologies (2L1, L2 and L3): Are the difficulties in the interfaces?).

We have pointed out that it is not always possible to discuss particular phenomena in terms of a single interface and our impression is that theorists and acquisitionists are increasingly acknowledging this fact. Although it used to be the case that certain properties were considered as pertaining to only one particular interface, recent studies have begun to examine the effects of multiple interface integration on language development and language production. In this contribution, we have presented articles as a multiple interface, but we could have found reasons to do the same for the other phenomena we presented. For instance, one could claim that the presence of an overt pronoun to mark focus in Romance languages also invokes the phonological interface, since focus involves differences in prosodic contours. Similarly, we described grammatical gender as a phenomenon interfacing with morphology, but we also pointed out that gender assignment may depend on the phonological properties of the noun. Of course, the dynamic nature of domains that evoke multiple interfaces add complexity both for empirical testing and the processing load in all learner types, and these complexities might manifest differently in performance and competence in various populations.

In this same vein, although there are striking parallels between learner populations in acquisition and development, such parallels do not imply that all learners behave alike with respect to all or even a majority of particular properties. As White (2011) points out, not all properties pertaining to specific interfaces are equally difficult to acquire, and it does not seem to be the case that a neat divide between internal and external interfaces correctly predicts which properties be subject to protracted development, emerging optionality and/or residual optionality. Success and failure across different studies may depend more on methodological differences than anything else. For example, heritage speakers are more likely to succeed in oral tasks than L2ers, while L2ers, in turn, might outperform heritage speakers in written grammaticality judgment tasks. Therefore, the claim that one interface is more vulnerable than the other should be based on comparison of the same populations of speakers, tested with the same methods. So far, very few studies have done so, which makes it hard to substantiate any claims about the relative vulnerability of interfaces.

What we do know for sure from the multitude of studies is that integration of information (linguistic and/or other) is not always straightforward and can interact with other variables to show differences in development and ultimate attainment across monolinguals and bilinguals. It seems rather uncontroversial that narrow syntax phenomena, i.e. the rare occasions where a property does not (substantially) interact with anything else, e.g. adjective placement in German, are relatively unproblematic in acquisition. Moreover, while acknowledging that the nature of interfaces is highly theory-dependent, we believe that the many studies reviewed in this chapter - including the many more that space and our narrow foci did not allow 
us to review directly - have shown that studies in the acquisition of Romance languages have made considerable contributions to the general research programs interested in linguistic interfaces.

\section{References}

Alemán Bañón, José/Fiorentino, Robert/Gabriele, Alison (2014), “Morphosyntactic processing in advanced second language learners. An event related potential investigation of the effects of L1-L2 similarity and structural distance", Second Language Research 30, 275-306.

Alemán Bañón, José/Miller, David/Rothman, Jason (2015), "Examining the nature of morphological variability in the online comprehension and production of number and gender agreement in L2 Spanish. An event related potential investigation", paper presented at Generative Approaches to Second Language Acquisition (GASLA) 2015, Indiana University.

Alexiadou, Artemis/Anagnostopoulou, Elena (1998), "Parametrizing AGR. Word order, V-movement and EPP-checking”, Natural Language and Linguistic Theory 16, 491-539.

Anderson, Bruce (2008), "Forms of evidence and grammatical development in the acquisition of adjective position in L2 French", Studies in Second Language Acquisition 30, 1-29.

Antelmi, Donella (1997), La prima grammatica italiana, Bologna, il Mulino.

Austin, Jennifer/Blume, María/Parkinson, David/Núñez del Prado, Zelmira/Lust, Barbara (1997), "The status of pro-drop in the initial state", in: Ana Teresa Pérez-Leroux/William Glass (edd.), Contemporary perspectives on the acquisition of Spanish, Somerville, MA, Cascadilla Press, 37-54.

Bartning, Inge (2000), “Gender agreement in L2 French. Preadvanced vs. advanced learners”, Studia Linguistica 54, 225-237.

Barton, Dagmar (2015), Generische Nominalphrasen bei deutsch-französischer Zweisprachigkeit. Zur Verwendung des Definitartikels bei erwachsenen Herkunftssprechern, PhD dissertation, Universität Hamburg.

Bassano, Dominique/Korecky-Köll, Katherina/Maillochon, Isabelle/Dressler, Wolfgang U. (2013a), "The acquisition of nominal determiners in French and German. A crosslinguistic perspective on the grammaticalization of nouns", in: Dominique Bassano/Maya Hickmann (edd.), Grammaticalization and first fanguage acquisition. Crosslinguistic perspectives, Amsterdam/ Philadelphia, Benjamins, 37-59.

Bassano, Dominique Korecky-Köll, Katherina/Maillochon, Isabelle/van Dijk, Marijn/Laaha, Sabine/ van Geert, Paul/Dressler, Wolfgang U. (2013b), "Prosody and animacy in the development of noun determiner use. A cross-linguistic approach", First Language 33, 476-503.

Bassano, Dominique/Maillochon, Isabelle/Mottet, Sylvain (2008), "Noun grammaticalization and determiner use in French children's speech. A gradual development with prosodic and lexical influences", Journal of Child Language 35, 403-438.

Bel, Aurora (2001), "Sujetos nulos y sujetos explícitos en las gramáticas iniciales del castellano y el catalán”, Revista Española de Lingüística 31:2, 537-561.

Bel, Aurora (2003), “The syntax of subjects in the acquisition of Spanish and Catalan”, Probus 15:1, $1-26$.

Belletti, Adriana/Bennati, Elisa/Sorace, Antonella (2007), "Theoretical and developmental issues in the syntax of subjects. Evidence from near-native Italian", Natural Language and Linguistic Theory 25, 657-689.

Bernardini, Petra (2003), “Child and adult acquisition of word order”, in: Natascha Müller (ed.), (In)vulnerable domains, Amsterdam/Philadelphia, Benjamins, 41-84. 
Bianchi, Giulia (2013), “Gender in Italian-German bilinguals. A comparison with German L2 learners of Italian”, Bilingualism. Language and Cognition, 538-557.

Bohnacker, Ute (1997), “Determiner Phrases and the debate on functional categories in early child language”, Language Acquisition 1, 49-90.

Bottari, Piero/Cipriani, Paola/Chilosi, Anna Maria (1993/1994), "Protosyntactic devices in the acquisition of Italian free morphology", Language Acquisition 3, 327-369.

Camacho, José (2013), Null Subjects, Cambridge, Cambridge University Press.

Cardinaletti, Anna/Giusti, Giulia (2010), “The acquisition of adjectival ordering in Italian”, in: Merete Anderssen/Kristine Bentzen/Marit Westergaard (edd.), Variation in the input, Dordrecht, Springer, 65-93.

Carroll, Susanne (1989), “Second language acquisition and the computational paradigm”, Language Learning 39:4, 535-594.

Caselli, Maria Cristina/Leonard, Laurence/Volterra, Virginia/Campagnoli, Maria Grazia (1993), "Toward mastery of Italian morphology. A cross-sectional study", Journal of Child Language 20, 377-393.

Chierchia, Gennaro (1998), “Reference to kinds across languages”, Natural Language Semantics 6, 339-405.

Chierchia, Gennaro/Guasti, Maria Teresa/Gualmini, Andrea (1999), “Nouns and articles in child grammar and the syntax/semantics map", Paper presented at GALA, Potsdam, Germany.

Chini, Marina (1995), Genere grammaticale e acquisizione. Aspetti della morfologia nominale in italiano L2, Milano, Angeli.

Chomsky, Noam (1957), Syntactic structures, The Hague, De Gruyter.

Cinque, Giuglielmo (2010), The syntax of adjectives. A comparative study, Cambridge, MA, MIT Press.

Clark, Eve (1985), “The acquisition of Romance with special reference to French”, in: Dan I. Slobin (ed.), The crosslinguistic study of language acquisition, vol. 1, Hillsdale, Erlbaum, 687-782.

Coppieters, René (1987), "Competence differences between native and near-native speakers", Language 63, 544-573.

Corrêa, Letícia/Name, Maria (2003), “The processing of determiner-noun agreement and the identification of the gender of nouns in the early acquisition of Portuguese", Journal of Portuguese Linguistics 2, 19-43.

Cuza, Alejandro/Guijarro-Fuentes, Pedro/Pires, Acrisio/Rothman, Jason (2013), "The syntax-semantics of bare and definite plural subjects in the L2 Spanish of English natives", International Journal of Bilingualism 17, 634-652.

Dewaele, Jean-Marc/Véronique, Daniel (2001), “Gender assignment and gender agreement in advanced French interlanguage. A cross-sectional study", Bilingualism. Language and Cognition 4:3, 275-297.

Döpke, Susanne (1998), “Competing language structures: the acquisition of verb placement by bilingual German-English children”, Journal of Child Language 25, 555-584.

Ezeizabarrena, María José (2002), "Root infinitives in two pro-drop languages", in: Ana Pérez-Leroux/ Juana Muñoz Liceras (edd.), The acquisition of Spanish syntax. The L1/l2 connection, Dordrecht, Kluwer, 35-65.

Fodor, Jerry A. (1983), The modularity of mind. An essay on faculty psychology, Cambridge, MA, MIT Press.

Gabriele, Alison/Fiorentino, Robert/Alemán Bañón, José (2013), “Examining second language development using event-related potentials. A cross-sectional study on the processing of gender and number agreement", Linguistic Approaches to Bilingualism 3, 213-232.

Giusti, Giuliana (2006), "Parallels in clausal and nominal periphery”, in: Mara Frascarelli (ed.), Phases of interpretation, Berlin/New York, De Gruyter, 163-184. 
Goad, Heather/White, Lydia (2009), "Prosodic transfer and determiners in Turkish-English interlanguage”, in: Neal Snape/Yan-kit I. Leung/Michael Sharwood Smith (edd.), Representational deficits in L2 acquisition, Amsterdam/Philadelphia, Benjamins, 1-26.

Granfeldt, Jonas (2000), "The acquisition of the determiner phrase in bilingual and second language French", Bilingualism. Language and Cognition 3:3, 263-280.

Granfeldt, Jonas (2003), L'acquisition des catégories fonctionnelles. Étude comparative du développement du DP français chez des enfants et des adultes, PhD dissertation, Lund, Lund University.

Granfeldt, Jonas (2005), "The development of gender assignment in bilingual first and second language French", in: Jean-M. Dewaele (ed.), Focus on French a foreign language. Multidisciplinary approaches, Clevedon, Multilingual Matters, 164-190.

Granfeldt, Jonas/Schlyter, Susanne/Kihlstedt, Maria (2007), "French as CL2, 2 L1 and L1 in pre-school children", in: Jonas Granfeldt (ed.), PERLES 24. Studies in Romance Bilingual Acquisition-Age of Onset and Development of French and Spanish, Lund, Lund University, 7-42.

Grinstead, John, (2004), "Subjects and interface delay in child Spanish and Catalan”, Language 80, 40-72.

Guasti, Maria Teresa (1993/1994), "Verb syntax in Italian child grammar. Finite and non-finite verbs", Language Acquisition 4, 1-40.

Guasti, Maria Teresa (2002), Language Acquisition. The growth of grammar, Cambridge, MA, MIT Press.

Guasti, Maria Teresa/De Lange, Joke/Gavarró, Anna/Caprin, Claudia (2004), "Article omission. Across child languages and across special registers", in: Jacqueline van Kampen/Sergio Baauw (edd.), Proceedings of Gala 2003, vol. 1, Utrecht, Lot Occasional Series, 199-210.

Hawkins, Roger/Franceschina, Florencia (2004), "Explaining the acquisition and non-acquisition of determiner-noun gender concord in French and Spanish", in: Philippe Prévost/Johanne Paradis (edd.), The acquisition of French in different contexts, Amsterdam/Philadelphia, Benjamins, 175-205.

Haznedar, Belma (2013), “Child second language acquisition from a generative perspective", Linguistic Approaches to Bilingualism 3, 26-47.

Hickmann, Maya/Hendricks, Henriëtte (1999), “Cohesive anaphoric relations in children's narratives as a function of mutual knowledge", First Language 15, 277-300.

Hilles, Sharon (1986), "Interlanguage and the pro-drop parameter", Second Language Research 2, 33-52.

Holmberg, Anders/Nayudu, Aarti/Sheehan, Michelle (2009), “Three partial null-subject languages. A comparison of Brazilian Portuguese, Finnish and Marathi”, Studia Linguistica 63, 59-97.

Hulk, Aafke (2004), "The acquisition of the French DP in a bilingual context", in: Philippe Prévost/ Johanne Paradis (edd.), The acquisition of French in different contexts. Focus on functional categories, Amsterdam/Philadelphia, Benjamins, 243-274.

Hulk, Aafke/Müller, Natascha (2000), "Cross-linguistic influence at the interface between syntax and pragmatics", Bilingualism. Language and Cognition 3, 227-244.

Hyams, Nina (1986), Language acquisition and the theory of parameters, Dordrecht, Reidel.

Hyams, Nina (1988), “A principles-and-parameters approach to the study of child language”, Papers and Reports on Child Language Development 27, 153-161.

Hyams, Nina/Wexler, Kenneth (1993), "On the grammatical basis of null subjects in child language", Linguistic Inquiry 24, 421-459.

Ionin, Tania/Grolla, Elaine/Montrul, Silvina/Santos, Hélade (2014), "When articles have different meanings. Acquiring the expression of genericity in English and Brazilian Portuguese", in: Patricia Cabredo Hofherr/Anne Zribi-Hertz (edd.), Crosslinguistic studies on noun phrase structure and reference, Syntax and Semantics, vol. 39, Leiden, Brill, 367-397. 
Ionin, Tania/Ko, Heejong/Wexler, Ken (2004), “Article semantics in L2 acquisition. The role of specificity”, Language Acquisition 12, 3-69.

Ionin, Tania/Montrul, Silvina (2009), “Article use and generic reference. Parallels between L1- and L2-acquisition”, in: María del Pilar García Mayo/Roger Hawkins (edd.), Second language acquisition of articles. Empirical findings and theoretical implications, Amsterdam/Philadelphia, Benjamins, 147-174.

Ionin, Tania/Montrul, Silvina (2010), “The role of L1-transfer in the interpretation of articles with definite plurals in L2-English", Language Learning 60, 877-925.

Jaeggli, Osvaldo/Safir, Kenneth (1989), “The null subject parameter and parametric theory”, in: Osvaldo Jaeggli/Kenneth Safir (edd.), The null subject parameter, Dordrecht, Kluwer, 1-44.

Karmiloff-Smith, Annette (1979), A functional approach to child language, Cambridge, Cambridge University Press.

Kuchenbrandt, Imme (2005), “Gender acquisition in bilingual Spanish”, in: James Cohen/Kara T. McAlister/Kellie Rolstad/Jeff MacSwan (edd.), ISB4. Proceedings of the 4th International Symposium on Bilingualism, Somerville, MA, Cascadilla Press, 1252-1263.

Kuchenbrandt, Imme (2008), “Cross-linguistic influences in the acquisition of grammatical gender?”, in: Arbeiten zur Mehrsprachigkeit, B 86, Hamburg, Sonderforschungsbereich Mehrsprachigkeit Universität Hamburg.

Kupisch, Tanja (2006), "The emergence of article forms and functions in a German-Italian bilingual child”, in: Conxita Lleó (ed.), Interfaces in multilingualism. Acquisition, representation and processing, Amsterdam/Philadelphia, Benjamins, 45-109.

Kupisch, Tanja (2007), "Determiners in bilingual German-Italian children. What they tell us about the relation between language influence and language dominance", Bilingualism. Language and Cognition 10, 57-78.

Kupisch, Tanja (2012), “Generic subjects in the Italian of early German-Italian bilinguals and German learners of Italian as a second language”, Bilingualism. Language and Cognition 15, 736-756.

Kupisch, Tanja (2014), “Adjective placement in simultaneous bilinguals (German-Italian) and the concept of cross-linguistic overcorrection”, Bilingualism. Language and Cognition 17, 222-233.

Kupisch, Tanja/Akpinar, Deniz/Stöhr, Antje (2013), “Gender assignment and gender agreement in adult bilingual and second language speakers of French", Linguistic Approaches to Bilingualism 3, 150-179.

Kupisch, Tanja/Anderssen, Merete/Bohnacker, Ute/Snape, Neal (2009), “Article acquisition in English, German, Norwegian and Swedish”, in: Ronald P. Leow/Héctor Campos/Donna Lardiere (edd.), Little words. Their history, phonology, syntax, semantics, pragmatics and acquisition, Washington, Georgetown University Press, 223-235.

Kupisch, Tanja/Lein, Tatjana/Barton, Dagmar/Stangen, Ilse/Schröder, Dawn Judith/Stöhr, Antje (2014), “Acquisition outcomes across domains in adult simultaneous bilinguals with French as weaker and stronger language", Journal of French Language Studies 24, 1-30.

Kupisch, Tanja/Müller, Natascha/Cantone, Katja (2002), "Gender in monolingual and bilingual first language acquisition. Comparing Italian and French", Lingue e Linguaggio 1, 107-149.

Kupisch, Tanja/Pierantozzi, Cristina (2010), “Interpreting definite plural subjects. A comparison of German and Italian monolingual and bilingual children", in: Katie Franich/Kate M. Iserman/ Lauren L. Keil (edd.), 34th Boston University Conference on Language and Development, Somerville, MA, Cascadilla Press, 245-254.

Lleó, Conxita (2001), “The interface of phonology and syntax. The emergence of the article in the early acquisition of Spanish and German", in: Jürgen Weissenborn/Barbara Höhle (edd.), Approaches to bootstrapping. Phonological, lexical, syntactic and neurophysiological aspects of early language acquisition, Amsterdam/Philadelphia, Benjamins, 23-44. 
Lleó, Conxita/Demuth, Katherine (1999), "Prosodic constraints on the emergence of grammatical morphemes. Cross-linguistic evidence from Germanic and Romance languages", in: Annabel Greenhill/Heather Littlefield/Cheryl Tano (edd.), Proceedings of the 23rd Annual Boston University Conference on Child Language Development, Somerville, MA, Cascadilla Press, 407-418.

Longobardi, Giuseppe (1994), "Reference and proper names. A theory of N-movement in syntax and Logical Form”, Linguistic Inquiry 25, 609-665.

Lozano, Cristóbal (2002), "Knowledge of expletive and pronominal subjects by learners of Spanish", ITL Review of Applied Linguistics 135, 37-60.

Madeira, Ana Maria/Xavier, Francisca/Crispim, Maria de Lourdes (2012), "Uso e interpretação de sujeitos pronominais em português L2", in: Armanda Costa/Cristina Flores/Nélia Alexandre (edd.), Textos Selecionados do XXVII Encontro da Associação Portuguesa de Linguística, Lisboa, Associação Portuguesa de Linguística, 376-397.

Meisel, Jürgen M. (2009), "Second language acquisition in early childhood", Zeitschrift für Sprachwissenschaft 28, 5-34.

Meisel, Jürgen M. (2011), First and second language acquisition. Parallels and differences, Cambridge, Cambridge University Press.

Montalbetti, Mario (1984), After Binding. On the interpretation of pronouns, PhD dissertation, Massachusetts Institute of Technology.

Montrul, Silvina (2004), "Subject and object expression in Spanish heritage speakers. A case of morphosyntactic convergence", Bilingualism. Language and Cognition 7, 125-142.

Montrul, Silvina (2008), Incomplete acquisition in bilingualism. Re-examining the age factor, Amsterdam/Philadelphia, Benjamins.

Montrul, Silvina/Foote, Rebecca/Perpiñán, Silvia (2008), "Gender agreement in adult second language learners and adult Spanish heritage speakers. The effects of age and context of acquisition", Language Learning 58, 503-553.

Montrul, Silvana/Ionin, Tania (2010), "Transfer effects in the interpretation of definite articles by Spanish heritage speakers", Bilingualism. Language and Cognition 13:4, 449-473.

Müller, Natascha (1990), "Developing to gender assignment systems simultaneously”, in: Jürgen M. Meisel (ed.), Two first languages. Early grammatical development in bilingual children, Amsterdam/Philadelphia, Benjamins, 193-234.

Müller, Natascha (1999), “Gender and number in acquisition”, in: Barbara Unterbeck/Matti Rissanen (edd.), Gender in grammar and cognition, Berlin/New York, De Gruyter, 351-399.

Munn, Alan/Schmitt, Cristina (1999), "Bare nouns and the morphosyntax of number", in: Teresa Satterfield/Christina Tortora/Diana Cresti (edd.), Current issues in Romance languages, Amsterdam/Philadelphia, Benjamins, 225-240.

Muñoz Liceras, Juana (1989), “On some properties of the 'pro-drop' parameter. Looking for missing subjects in non-native Spanish", in: Susan M. Gass/Jacquelyn Schachter (edd.), Linguistic perspectives on Second Language Acquisition, Cambridge, Cambridge University Press, 109-133.

Nicoladis, Elena (2006), "Cross-linguistic transfer in adjective-noun strings by preschool bilingual children”, Bilingualism. Language and Cognition 9, 15-32.

Paradis, Johanne/Navarro, Samuel (2003), "Subject realization and crosslinguistic interference in the bilingual acquisition of Spanish and English. What is the role of input?", Journal of Child Language 30, 371-393.

Pérez-Leroux, Ana Teresa/Glass, William (1999), “Null anaphora in Spanish second language acquisition. Probabilistic versus generative approaches", Second Language Research 15, 220-249.

Pérez-Leroux, Ana Teresa/Munn, Alan/Schmitt, Cristina/Delrish, Michelle (2004), "Learning definite determiners. Genericity and definiteness in English and Spanish", in: Alejna Brugos/Linnea Micciulla/Christine E. Smith (edd.), Proceedings Supplement of the 28th BUCLD, http://www. bu.edu/bucld/proceedings/supplement/vol28/ (06.12.2011). 
Pérez Pereira, Miguel (1991), “The acquisition of gender. What Spanish children tell us”, Journal of Child Language 18, 571-590.

Phinney, Marianne (1987), “The pro-drop parameter in second language acquisition”, in: Thomas Roeper/Edwin Williams (edd.), Parameter setting, Boston, Reidel, 221-246.

Pinker, Steven (1994), The language instinct. The new science of language and mind, New York, NY, Harper.

Pires, Acrisio/Rothman, Jason (2009), "Disentangling sources of incomplete acquisition. An explanation for competence divergence across heritage grammars", International Journal of Bilingualism 13, 211-238.

Pizzuto, Elena/Caselli, Maria Cristina (1992), “The acquisition of Italian morphology. Implications for models of language development", Journal of Child Language 19, 491-557.

Platzack, Christer (2001), “The vulnerable C-domain”, Brain and Language 77, 364-377.

Rizzi, Luigi (1982), Issues in Italian syntax, Dordrecht, Foris.

Rizzi, Luigi (1994), "Some notes on linguistic theory and language development. The case of root infinitives", Language Acquisition 3, 371-393.

Rizzi, Luigi (2002), On the grammatical basis of language development. A case study, Ms. University of Siena.

Rizzi, Silvana/Arnaus Gil, Laia/Repetto, Valentina/Geveler, Jasmin/Müller, Natascha (2013), “Adjective placement in bilingual Romance-Romance and Romance-German children with special reference to Romance (French, Italian and German)”, Studia Linguistica 67, 123-147.

Roodenburg, Jasper (2005), "Une coordination particulière. Les syntagmes N Conj N en français", Langages 160, 93-109.

Rothman, Jason (2007), "Pragmatic solutions for syntactic problems. Understanding some L2 syntactic errors in terms of pragmatic deficits", in: Sergio Baauw/Frank Drijkoningen/Manuela Pinto (edd.), Romance Languages and Linguistic Theory 2005, Amsterdam/Philadelphia, Benjamins, 299-320.

Rothman, Jason (2009a), "Understanding the Nature of Early Bilingualism: Romance Languages as Heritage Languages", International Journal of Bilingualism 13, 155-163.

Rothman, Jason (2009b), "Pragmatic deficits with syntactic consequences. L2 pronominal subjects and the syntax-pragmatics interface", Journal of Pragmatics 41, 951-973.

Rothman, Jason/Guijarro-Fuentes, Pedro (2012), "Linguistic interfaces and language acquisition in childhood", First Language 32, 3-17.

Rothman, Jason/Iverson, Michael (2007a), "On L2 clustering and resetting the null subject parameter in L2 Spanish. Implications and observations", Hispania 90, 329-342.

Rothman, Jason/Iverson, Michael (2007b), “Input type and parameter resetting. Is naturalistic input necessary?", International Review of Applied Linguistics 45, 285-319.

Rothman, Jason/Judy, Tiffany/Guijarro-Fuentes, Pedro/Pires, Acrisio (2010), "On the (un)ambiguity of adjectival interpretation in L2 Spanish. Informing debates on the mental representation of L2 syntax", Studies in Second Language Acquisition, 32, 47-77.

Rothman, Jason/Slabakova, Roumyana (2011), "The mind-context divide. On acquisition at the linguistic interfaces”, Lingua 121, 568-576.

Rozendaal, Margot (2008), The acquisition of reference. A cross-linguistic study, PhD dissertation, University of Amsterdam.

Rozendaal, Margot/Baker, Anne Edith (2008), "A cross-linguistic investigation of the acquisition of the pragmatics of indefinite and definite reference in two-year-olds", Journal of Child Language 35, 773-807.

Schwartz, Bonnie/Sprouse, Rex (1996), "L2 cognitive states and the full transfer/full access hypothesis", Second Language Research 12, 40-72.

Serratrice, Ludovica (2007), "Referential cohesion in the narratives of bilingual English-Italian children and monolingual peers", Journal of Pragmatics 39, 1058-1087. 
Serratrice, Ludovica (2013), "Cross-linguistic influence in bilingual development. Determinants and mechanisms", Linguistic Approaches to Bilingualism 3, 3-25.

Serratrice, Ludovica/Sorace, Antonella/Filiaci, Francesca/Baldo, Michela (2009), "Bilingual children's sensitivity to specificity and genericity. Evidence from metalinguistic awareness", Bilingualism. Language and Cognition 12, 239-257.

Slabakova, Roumyana (2006), “A semantic parameter with a syntactic trigger in the L2 acquisition of Italian”, in: Roumyana Slabakova/Silvana Montrul/Philippe Prévost (edd.), Inquiries in linguistic development. Studies in honor of Lydia White, Amsterdam/Philadelphia, Benjamins, 69-87.

Slabakova, Roumyana (2013), "Adult second language acquisition. A selective overview with a focus on the learner linguistic system", Linguistic Approaches to Bilingualism 3:1, 48-72.

Snyder, William (2007), Child language. The parametric approach, Oxford, Oxford University Press.

Sorace, Antonella (2004), "Native language attrition and developmental instability at the syntaxdiscourse interface. Data, interpretations and methods", Bilingualism. Language and Cognition 7, 143-145.

Sorace, Antonella (2011), "Pinning down the concept of 'interface' in bilingualism", Linguistic Approaches to Bilingualism 1, 1-34.

Sorace, Antonella (2012), “Pinning down the concept of 'interface' bilingual development. A reply to peer commentaries", Linguistic Approaches to Bilingualism 1, 209-217.

Sorace, Antonella/Filiaci, Francesca (2006), "Anaphora resolution in near-native speakers of Italian", Second Language Research 22, 339-368.

Sorace, Antonella/Serratrice, Ludovica (2009), "Internal and external interfaces in bilingual language development. Beyond structural overlap", International Journal of Bilingualism 13, 1-16.

Thordardóttir, Elin (to appear), "The relationship between bilingual exposure and morpho-syntactic development”, International Journal of speech Language Pathology, DOI: 10.3109/ 17549507.2014.923509.

Ticio, M. Emma (2002), "Dialectal variation in the acquisition of null subject parameter", in: João Costa/Maria João Freitas (edd.), Proceedings of Generative Approaches to Language Acquisition, Lisboa, Associação Portuguesa de Linguística, 271-278.

Trenkic, Danijela (2007), "Variability in L2 article production. Beyond the representational deficit vs. processing constraints debate", Second Language Research 23, 289-327.

Tsimpli, lanthi-Maria (2014), “Early, late or very late? Timing acquisition in bilingualism”, Linguistic Approaches to Bilingualism 4, 283-413.

Tsimpli, Ianthi-Maria/Dimitrakopoulou, Maria (2007), "The interpretability hypothesis. Evidence from wh-interrogatives in second language acquisition”, Second Language Research 23:2, 215-242.

Tsimpli, lanthi-Maria/Mastropavlou, Maria (2007), "Feature interpretability in L2 acquisition and SLI. Greek clitics and determiners”, in: Juana Muñoz Liceras/Helmut Zobl/Helen Goodluck (edd.), The role of formal features in second language acquisition, Mahwah, NJ, Erlbaum, 142-183.

Tucker, G. Richard/Lambert, Wallace E./Rigault, Aude (1977), The French speaker's skill with grammatical gender. An example of rule-governed behavior, The Hague, De Gruyter.

Valian, Virginia (1991), "Syntactic subject in the early speech of American and Italian children", Cognition 40:1-2, 21-81.

Valian, Virginia/Eisenberg, Zena (1996), "The development of syntactic subjects in Portuguesespeaking children", Journal of Child Language 23, 103-128.

van der Velde, Marlies/Jakubowicz, Célia/Rigaut, Catherine (2002), “The acquisition of determiners and pronominal clitics by three French-speaking children", in: Ingeborg Lasser (ed.), The process of language acquisition. Proceedings of the 1999 GALA conference, Frankfurt am Main, Lang, 115133. 
Volterra, Virginia/Taeschner, Traute (1978), “The acquisition and development of language by bilingual children", Journal of Child Language 5, 311-326.

White, Lydia (1985), “The pro-drop parameter in adult second language acquisition”, Language Learning 35, 47-62.

White, Lydia (1986), “Implications of parametric variation for adult second language acquisition. An investigation of the 'pro-drop' parameter", in: Vivian Cook (ed.), Experimental approaches to second language acquisition, Oxford, Pergamon, 55-72.

White, Lydia (2003), Second language acquisition and universal grammar, Cambridge, Cambridge University Press.

White, Lydia (2009), “Grammatical theory. Interfaces and L2 knowledge”, in: William C. Ritchie/Tej K. Bhatia (edd.), The new handbook of second language acquisition, Bingley, Emerald Group Publishing, 46-68.

White, Lydia (2011), “Second language acquisition at the interfaces”, Lingua 121, 577-590.

White, Lydia/Valenzuela, Elena/Kozlowska-Macgregor, Martyna/Leung, Ingrid (2004), "Gender agreement in nonnative Spanish. Evidence against failed features", Applied Psycholinguistics 2, 105-133. 
